\title{
Reliability and validity of the Finnish version of the prosthesis evaluation questionnaire
}

\section{Repo, Jussi Petteri}

2018

Repo , J P , Piitulainen , K, Häkkinen , A , Roine , R P, Kautiainen , H, Becker , P \& Tukiainen , E J 2018 , ' Reliability and validity of the Finnish version of the prosthesis evaluation questionnaire ' , Disability and Rehabilitation , vol. 40 , no. 17 , pp. 2081-2087 . https://doi.org/10.1080/09

http://hdl.handle.net/10138/311586

https://doi.org/10.1080/09638288.2017.1323032

acceptedVersion

Downloaded from Helda, University of Helsinki institutional repository.

This is an electronic reprint of the original article.

This reprint may differ from the original in pagination and typographic detail.

Please cite the original version. 
1 Reliability and validity of the Finnish version of the Prosthesis Evaluation

\section{Questionnaire}

4 Abstract

5 BACKGROUND Thus far there have been no specific patient-reported intruments in

6 Finnish for health-related quality of life assesment after major lower extremity

7 amputation and successful prosthesis fitting.

8 METHODS The Prosthesis Evaluation Questionnaire was translated and cross-

9 culturally adapted to Finnish. Participants completed a questionnaire package including

10 the Finnish version of the Prosthesis Evaluation Questionnaire and the 15D health-

11 related quality of life instrument. Scales $(n=10)$ were tested for internal consistency,

12 floor-ceiling effect, and reproducibility for which participants completed the Prothesis

13 Evaluation Questionnaire twice within a 2-week interval. Validity was tested by

14 estimating the correlation between the $15 \mathrm{D}$ index and the scales. The authors included

15122 participants who had completed the questionnaire on two separate occasions in the

16 final analysis.

17 RESULTS Mean scale scores of the 10 scales varied from 52 to 83 . Cronbach alphas

18 ranged from 0.67 to 0.96 . The total score showed no floor-ceiling effect.

19 Reproducibility of the scales was good (intraclass correlation coefficient, 0.78-0.87;

20 coefficient of repeatability, 19-36). Significant correlations were observed between the

21 15D index and the scales for Ambulation, Social Burden, Usefulness and Well-being.

22 CONCLUSIONS This study provided evidence of the reliability and validity of the

23 Finnish version of the Prothesis Evaluation Questionnaire in assessing the health-related

24 quality of life among major lower extremity amputated patients who have been fitted 25 with prosthesis. 
26 Key Words: Rehabilitation; Prosthesis; Validity; Reliability; Amputation;

27 Psychometrics

\section{Introduction}

30 Assessing rehabilitation effectiveness with high quality patient-reported outcome

31 instruments makes it possible to obtain an amputee-centered experience in a relevant

32 way [1]. Generic instruments that are designed to obtain information from a broad

33 variety of health parameters may not be specific enough to measure the specific

34 problems encountered by amputees. Thus, the Prosthesis Profile of the Amputee

35 questionnaire was introduced in 1994 to provide a tool for lower-extremity amputee-

36 specific assessment [2]. Qualitative studies may provide deep insight into patients'

37 biopsychosocial perspectives that otherwise would be hard to obtain. However,

38 quantitative data obtained from patient-reported instruments can provide accurate and

39 reliable outcomes that can be statistically analyzed for the assessment of effectiveness

40 of different methods of surgical approaches or rehabilitation.

42 The rehabilitation assessment further evolved towards emphasizing the impact of

43 rehabilitation on the health-related quality of life (HRQoL), when Legro et al.

44 developed and validated the English version of the Prosthesis Evaluation Questionnaire

45 (PEQ) [3]. The PEQ is an amputee-specific quality of life instrument that can be used to

46 assess the HRQoL of lower-extremity prosthesis users. It has been further

47 psychometrically investigated and validated after being translated into several other

48 languages [4-8]. Furthermore, the PEQ has been used in a great variety of studies [9].

50 There has hitherto been no validated lower-extremity amputee-specific patient-reported 
51 outcome instrument in Finnish. The authors aimed, therefore, to transculturally adapt

52 the English PEQ into a Finnish version, which was then tested for reliability and

53 validity among patients who have undergone major lower extremity amputation and

54 have rehabilitated to prosthesis users.

55

56 Methods

$57 \quad$ Ethical considerations and participants

58 The Ethics Committee of the Helsinki University Hospital approved the study. The

59 authors included in the study patients, who had undergone major lower extremity

60 amputation, were at least 18 years old, had full ability to understand written Finnish and

61 had rehabilitated to prosthesis users in the Helsinki and Uusimaa Hopital District or the

62 Central Finland Health Care District, Finland. The participants provided their written

63 consent according to the Helsinki Declaration. The authors approached by mail 597

64 consecutive patients who had undergone major lower extremity amputation and had

65 successful prosthesis fitting.

66

67 Translation and adaptation

68 The authors contacted the developer of the PEQ to obtain permission to use the English

69 language questionnaire. The translation and adaptation process adhered to the

70 International Society for Pharmacoeconomics and Outcomes Research guidelines [10].

71

72 Two native Finnish-speaking translators who were professionals in the field of

73 rehabilitation and fluent in English produced a forward-translation independently of

74 each other. Differences encountered between the two forward translations were

75 discussed by the steering group who then synthesized one forward-translation. A back- 
76 translation was produced by an English language-expert who was fluent in Finnish and

77 familiar with the Finnish culture and translating patient-reported outcome instruments

78 but unfamiliar with the current instrument. A back-translation panel consisting of all

79 three translators reviewed the translation drafts and compared them to the original

80 English version and provided a written report. In addition to this a language expert of

81 the Finnish Medical Society Duodecim was consulted when translation problems were

82 encountered. A multidisciplinary committee reviewed each part of the translation

83 processes separately.

84

85 The pre-final version underwent pre-testing together with cognitive debriefing among

8614 Finnish patients who had undergone transtibial amputation and who were transtibial

87 prosthesis users. The cognitive debriefing followed the European Organisation for

88 Research and Treatment of Cancer (EORTC) guidelines [11] to identify any offensive

89 content, problems with understandability, cultural relevance, difficulties in anwering or

90 in interpretation of the questions and whether the participants would ask any question

91 differently. In the last phase, the multidisciplinary committee reviewed the pre-testing

92 outcomes and interview reports. The final version was introduced and was then

93 proofread by the language expert of the Finnish Medical Society Duodecim

94 (Supplementary file).

95

$96 \quad$ Instruments

97 Prosthesis Evaluation Questionnaire. The lower extremity amputee-specific PEQ is a

98 valid, comprehensive instrument comprising 82 items with seven different main themes.

99 The items refer to the preceding four weeks. The PEQ also contains items with 
100 checkboxes for assessing topics such as Satisfaction, Pain, Transfers, Prosthesis care

101 and Self-efficacy. These items are scored individually.

102

103 The PEQ can be separated into 10 validated scales: Ambulation, Appearance,

104 Frustration, Perceived Response, Social Burden, Utility, Residual Limb Health, Sounds,

105 Transfers and Well-being [3]. The items are completed on a visual analogue scale (0-

$106100 \mathrm{~mm}$; from worst to best). The total scores for each scale are calculated through the

107 arithmetic mean of all items of the scale.

108

$10915 D$ instrument. The 15D is a valid, generic HRQoL instrument containing 15

110 dimensions: moving, seeing, hearing, breathing, sleeping, eating, speech, excretion,

111 usual activities, mental function, discomfort and symptoms, depression, distress, vitality

112 and sexual activity [12]. Respondents choose one of the five levels in each dimension

113 that best describes their current state of health (1-5; best to worst possible score). The

114 15D produces both a HRQoL profile and a single index score that represents the overall

115 HRQoL. The single index score ranges from 0 to 1 , with 0 equivalent to being dead and

1161 being in the best imaginable HRQoL state. Reproducibility and the minimum

117 important change of the $15 \mathrm{D}$ have been reported to be 0.90 and 0.015 , respectively

$118[13,14]$.

119

120 Sociodemographic and clinical questionnaire. The authors obtained information on

121 participants' age, sex, cause for amputation, comorbidities, amputation level

122 (disarticulation amputation was considered as above-knee amputation), time since

123 amputation, and beginning of the prosthesis use. In addition, a visual analogue scale on

124 a 0 to $100 \mathrm{~mm}$ scale (0-100 mm; best to worst) was used for measuring participants' 
125 self-reported general health and pain during the preceding week. The NRS is another

126 instruments as it is a segmented numeric version of the visual analog scale (VAS) in

127 which a respondent selects a whole number (0-10 integers) that best reflects the

128 intensity of their pain. The visual analog scale, which the authors used, is a widely

129 accepted measure and validated for pain assessment [15].

130

131

\section{$P E Q$ validation course and reproducibility setting}

132 In addition to the pre-information form, the authors included the following intruments

133 in the first questionnaire package: the Finnish PEQ, the 15D and the general health and

134 pain visual analogue scale questions. Participants returned the completed questionnaires

135 together with the signed informed consent. Potential participants who did not return the

136 first questionnaire set within a week received a reminder letter. After the participants

137 had completed the first questionnaire, the authors mailed them the PEQ instrument a

138 second time along with a survey. The purpose of both was to ascertain whether the

139 patients' health status had changed between completing the first round of

140 questionnaires. The authors included participants who had completed the PEQ twice in

141 the final analyses.

142

143 Statistics

144 The authors present the data as means with standard deviations (SD), medians with

145 interquartile ranges (IQR), 95\% confidence intervals $(95 \% \mathrm{CI})$, or as counts with

146 percentages or ranges. The scale completion rate is provided to illustrate the percentage

147 of missing items in the analysis. Predefined hypotheses were placed based on the

148 existing literature or general presumptions [table 1].

149 
150 A one-way random-effects model with absolute agreement was used to measure relative

151 reliability or intraclass correlation coefficient. The intraclass correlation coefficient

152 value was classified according to Cicchetti et al. as poor $(<0.40)$, fair $(0.40-0.59)$, good

$153(0.60-0.74)$ or excellent $(0.75-1.00)$ [16].

154

155 The internal consistency was estimated by calculating Cronbach's alpha [17] with

156 bootstrapped 95\% CIs.

157

158 The coefficient of repeatability expressed the expected maximum size of $95 \%$ of the

159 absolute differences between paired observations. The 95\% CI was obtained by bias

160 corrected and accelerated bootstrapping (5000 replications).

161

162 The Pearson method served to calculate the correlation coefficients. Statistical

163 significance in the correlation coefficient was set at $\mathrm{p}<0.05$ and calculated using Sidak-

164 adjusted probabilities. Bias-corrected bootstrapping was used to obtain the confidence

165 intervals for the mean changes between the two measurements and reproducibility.

166

167 The authors used linear regression analyses to identify the appropriate predictors of the

$16815 \mathrm{D}$ age- and gender-standardized regression coefficients Beta $(\beta)$. The $\beta$-value is a

169 measure of how strongly each predictor variable influences the criterion (dependent)

170 variable. The $\beta$ was measured in units of standard deviation. Cohen's standard for $\beta$ -

171 values above $0.10,0.30$ and 0.50 represent small, moderate and large relationships,

172 respectively.

173

174 


\section{Results}

176 Of the 167 participants (response rate, 28\%), who returned the questionnaires together

177 with their signed written consent, a total of 122 patients $(73 \%)$ had completed both the

178 first and the second questionnaires and were included in the study. The participants'

179 ages ranged from 19 to 93 [table 2]. The most common indication for primary major

180 lower-extremity amputation was vascular disease (29.5\%). Thirty-six percent $(n=44)$

181 of participants reported having no comorbidities [table 2]. The time from amputation to 182 completion of the outcome measures varied from four months to 69 years. Fifty percent

183 of the participants had undergone amputation less than five years earlier.

184

185 Translation and adaptation

186 Minor linguistic differences were noted between the two forward translations. A back-

187 translation panel review revealed no major problems between the back-translation and

188 the original English version. The multidisciplinary committee required that "rate the

189 weight of your prosthesis" in item 1C be changed to "evaluate the weight of your

190 prosthesis" in order to improve the Finnish. Item 1N required amending "prosthesis

191 cover" to "cosmetic surface" which is preferred in Finnish. In item 1Q the word

192 "stump" was added for clarification. In the Finnish language, the word "stump" is well

193 accepted to describe the distal end of an amputated limb. Translation of the words: "

194 "shooting", "searing", "stabbing", "sharp", "ache" in the "Group 2" of the PEQ

195 instrument required the help of the language expert to find suitable matches in Finnish.

196 The pre-testing and participants' cognitive debriefing gave no reason for changes. 
200

\section{Reliability}

201 Floor-ceiling effect. The PEQ showed no floor-effect (0 score) on the total score. Nine

202

203

204

205

206

207

208

209

210

211

212

213

214

215 Validity

216 Convergent validity. Pearson correlation coefficients between the PEQ scales and age

217

218

219

220

221

222

223

of the scales had no floor effect. Altogerher $1 \%$ had the lowest score in Ampulation

scale. A ceiling effect of one to five percent was found in five of the scales [table 3].

The highest ceiling effect was strongest in the Perceived Responses scale (5\%).

Internal consistency. Cronbach's alpha for the 10 scales revealed an internal

consistency ranging from 0.67 (Appearance) to 0.96 (Ambulation) [table 3].

Reproducibility. The mean value (SD) of the PEQ subscales at measurement one was

65.1 (23.7) (table 4). The mean change between the two measurement times ranged

from 0.0 to 2.1 in the separate scales. All scales had good reproducibility [table 4]. The coefficient of repeatability ranged from 19 for Usefulness to 36 for the Frustration scales [table 4].

were low (range, -0.28 to 0.15 ) [table 5]. The correlation of the PEQ scale scores with

time since prosthetization was also poor. Strong correlation was found between general

pain or general health and Usefulness, Ambulation, Transfers, Perceived responses,

Social Burden and Well-Being scales.

Strong correlation was found between the15D index and the scales of Ambulation

Social burden, Transfers, Usefulness and Well-being [Figure 1]. 


\section{Discussion}

226 The authors successfully produced a Finnish PEQ instrument and evaluated its

227 psychometric properties. To the authors' knowledge this study has the largest study

228 population to assess the psychometrics of the PEQ. The psychometric analyses showed

229 evidence of good reproducibility and validity for the Finnish PEQ. The Finnish version

230 of the PEQ instrument can now be used to assess the effectiveness of different

231 amputation techniques, stump reconstruction methods, and rehabilitation after

232 successful prosthesis fitting.

233

\section{Translation and adaptation}

235 The translation and cross-cultural adaptation process adhered rigorously to the

236 International Society for Pharmacoeconomics and Outcomes Research guidelines [10].

237 All the discrepancies and changes made during the translation phases were meticulously

238 recorded in written reports. One previous translation report addressed the linguistic or

239 cultural problems encountered during the translation process [5]. The authors found

240 that adjustments were required to adjust for linguistic differences between the Finnish

241 version of the PEQ and the original English version.

242

243 In the Arabic translation of the PEQ, the authors found the word "phantom" could be

244 interpreted as a "ghost sensation" among the Saudi people [5]. The word "phantom"

245 does not have a negative connotation in Finnish nor is it linked to ghosts. The

246 identification of items in the Arabic version was changed to match the group number

247 rather than the page number as in the original English version [3,5]. The Finnish version

248 also uses the group numbers to identify the items. The new numbering of items should

249 be taken into consideration when using the Finnish PEQ. 
250

251 A floor-ceiling effect of less than $15 \%$ is considered acceptable [18]. Reliability testing for the PEQ by Legro et al. found a floor effect of $22 \%$ in the scales of Frustration and a

253 ceiling effect of $25 \%$ in the Transfers scale in a similar study population to that of the

254 present study [3]. No explanation for this was provided by the Legro group. It could be hypothesized however that the ceiling effect was a consequence of the answers of those participants who had been amputated 9 to 28 years before assessment took place as they received the highest scores in the Transfers scale [3]. Other validation studies of PEQ did not report floor-ceiling values [5-8]. In the present study, five percent of participants received the maximum score in the Perceived Responses scale. Not a single participant reported the maximum scores in the Transfers scale. The PEQ scales of the Finnish version seemed to have no floor or ceiling effect based on the present study's findings. Thus, the present analysis provided evidence that it is somewhat unlikely that the PEQ would yield inaccurate maximum scores.

264

The internal consistency of the original English PEQ varies between 0.67 and 0.89 in the 10 scales [3]. Cronhach's alphas between 0.67 and 0.96 were noted in the present study. According to the literature, Cronbach's alpha of 0.8 or more is considered sufficient [19]. In the present study four of the 10 subscales were slightly lower than the proposed benchmark, but these values can be considered acceptable. Benavent et al. found poor internal consistency in the scales of Appearance and Residual Limb (0.37 and 0.15 , respectively) [8]. Cronbach's alpha varied in the remaining scales between 0.55 and 0.93 in that study [8]. Other studies have reported the internal consistency of Appearance and Residual Limb Health of 0.73-0.77 and 0.77-0.80, respectively [3,6,7].

274 The results of the present study were similar to those the previous studies $[3,6,7]$ as the 
275 internal consistency of the Appearance scale was 0.79 and that of the Residual Limb

276 was 0.67 . Internal consistency of the other eight scales were also mainly in concordance

277 with previously published literature [3,6-8]. The internal consistency in the present

278 study was below 0.9 in all scales, indicating that there was no item repetition [20].

279 The authors assessed reproducibility after a mean interval of two weeks. The

280 participants' health was stable in the interim period. The optimal interim time between

281 the two assessments has previously been placed at two weeks in assessment of the

282 reproducibility in situations where there is no acute change in the participants' health

283 [21]. According to the classification by Cicchetti et al. [14], all scales used in the

284 Finnish PEQ had excellent intraclass correlation coefficient values (0.78-0.87). Conrad

285 and colleagues reported intraclass correlation coefficient values that ranged from good

286 (0.65, Well-being) to excellent (0.92, Ambulation) between the scales in the Brazilian

287 Portuguese version of the PEQ [6]. However, the Conrad group reported on a smaller

288 study population that consisted only of 65 patients who had undergone major lower-

289 extremity amputation [6]. The authors also calculated the coefficient of repeatability for

290 the PEQ scales. The coefficient of repeatability can be used to obtain the value for

291 absolute reliability, the expected maximum size of $95 \%$ of the absolute differences

292 between paired observations. The present study reflects the good reproducibility of the

293 PEQ instrument scales. The authors found that the coefficient of repeatability ranged

294 from 19 to 36 between the different scales in the present study. The alternative of

295 calculating the coefficient of repeatability values may be more accurate compared to the

296 standard error of measurement as it takes into account both random and systematic

297 errors [22].

298

299 
300

301 Age has previously been reported to correlate with Residual Limb Health and

302 Frustration scale [3]. In the study by Legro et al., scores were higher in patients who

303 were younger than 40 years old [3]. The present study found low negative correlation

304 between age and Usefulness and Ambulation. The negative value indicates that as the

305 age of the patient increases, the worse the score gets. Locomotor activity might be

306 decreased in older individuals, which could explain the correlation. Interestingly, time

307 from prosthesis fitting to assessment had no correlation with the PEQ score, which

308 supports the findings reported by Legro and colleagues [3]. Both general health and

309 general pain correlated strongly with the scales of Usefulness, Ambulation, Transfers,

310 Perceived Responses, Social Burden and Well-being. Previous psychometric studies of

311 the PEQ have not assessed scale correlations with separate measurements of general

312 health or general pain [3-8]. However, the Usefulness scale correlated well with General

313 Health summary score in the study by Benavent et al.[8], which also supports the

314 findings of the present study.

315

316 The authors found a notable relationship between the scales of Ambulation, Social

317 burden, Usefulness and Well-being and the 15D HRQoL index in the construct validity

318 analysis [Figure 1]. The evidence suggests that PEQ has good criteria validity when it

319 comes to assessing HRQoL. Previously there has been no validated prosthesis-related

320 quality of life instrument in Finnish. Evidence of validity of the PEQ presented here

321 supports its use to assess the HRQoL of patients who have undergone major lower

322 extremity amputation and have been fitted with prosthesis. Legro et al. found strong

323 correlation with Ambulation and the SF-36 summary score of Physical Function ( $r=$

324 0.61) [3]. Further, Benavent and others [8] found that there was strong correlation 
325 between the Ambulation scale and the SF-36 summary scores of General Health ( $r=$

$3260.71)$, Vitality $(r=0.73)$, Social Function $(r=0.78$ and Mental Health $(r=0.67)$. A strong

327 correlation $(r=0.73)$ between the PEQ Social Burden scale and the SF-36 Social

328 Function summary score was also found. The authors used the 15D HRQoL instrument

329 in the present study as it is widely accepted in health care internationally and especially

330 in Finland. The 15D can be linked to the ICF-classification [23]. Its properties have

331 proven superior to several other widely used HRQoL patient-reported instruments

$332[13,14,24,25,26]$.

333

\section{Clinical applications}

335 Amputation has a significant impact on patients' lives. Optimally, rehabilitation allows

336 the patients to return to their previous daily activities and social affairs. However,

337 prosthesis fitting and rehabilitation cause notable cost to society. There is a need for

338 assessment tools in measuring the need of treatment and rehabilitation as well as their

339 effectiveness. Several different techniques (e.g. in flap design) are used for major lower

340 extremity amputation. Furthermore, the amputation stump may not always have a

341 sufficient amount of healthy soft tissue for local flap stump coverage and microvascular

342 reconstruction or bone-lengthening techniques are thus needed in selected cases. These

343 surgical techniques may have an impact on how the prosthesis fits. Inadequate

344 rehabilitation methods may lead to poor results and abandonment of the prosthesis. The

345 effectiveness of different surgical methods and rehabilitation processes and their impact

346 on health-related quality of life can be assessed using the PEQ instrument in patients

347 who have been fitted with prosthesis. However, the PEQ is a comprehensive

348 questionnaire that has a large amount of items $(\mathrm{N}=82)$. It gives extensive information 
349 about the patient and prosthesis use. The 10 validated scales might be better in clinical

350 practice as they can be used as a patient profile.

351

\section{$352 \quad$ Strengths and limitations}

353 The study recruited a heterogeneous population of patients who had undergone major

354 lower extremity amputation. Some may consider this approach as a weakness. However,

355 a heterogeneous study population allows a better generalization to be made about the 356 outcomes of this study. One limitation was the low response rate that, nonetheless, can

357 be considered acceptable for a psychometric study. Previous studies have shown that

358 ischaemia is the major cause or major lower extremity amputation [27]. However, no

359 epidemiological studies have been conducted to provide information of the amputation

360 etiology of patients who are fitted with prosthesis. Using several reference outcomes

361 would have brought even deeper knowledge of the convergent validity of the Finnish

362 PEQ. However, the authors did not have another validated amputee-specific instrument

363 in Finnish to compare. Francihignoni et al. analyzed the PEQ Ambulation scale using

364 item response theory [4]. A single item was omitted and a 5-point answer scale

365 established [4]. A Rasch analysis could have provided even more insight into the

366 construct validity of the Finnish PEQ in the present study. Further studies should

367 therefore aim to assess the construct of the PEQ scales using inter alia Rasch analysis

368 and the responsiveness with a longitudinal study design.

369

370 Conclusions

371 The authors conclude that the PEQ instrument was succesfully translated and cross-

372 culturally adapted into the Finnish language version. Psychometric testing of the

373 Finnish version of the PEQ showed evidence of its reliability and validity in assessing 
374 prosthesis-related quality of life in patients who have undergone major lower extremity

375 amputation and who have rehabilitated to prosthesis users. The Finnish PEQ is a

376 suitable patient-reported outcome instrument for clinical use and in scientific studies for

377 assessing the efficacy and outcomes of different amputation techniques, stump

378 reconstruction methods, and rehabilitation in patients who have been fitted with

379 prosthesis.

380

381 Declaration of Interests The authors report no conflicts of interest.

382

\section{References}

384 1. Hawkins AT, Henry AJ, Crandell DM, Nguyen LL. A systematic review of

385 functional and quality of life assessment after major lower extremity amputation. Ann

386 Vasc Surg. 2014;28(3):763-80.

387 2. Gauthier-Gagnon C, Grisé MC. Prosthetic profile of the amputee questionnaire:

388 validity and reliability. Arch Phys Med Rehabil 1994;75(12):1309-14.

389 3. Legro MW, Reiber GD, Smith DG, del Aguila M, Larsen J, Boone D. Prosthesis

390 evaluation questionnaire for persons with lower limb amputations: assessing prosthesis-

391 related quality of life. Arch Phys Med Rehabil 1998;79(8):931-8.

392 4. Franchignoni F, Giordano A, Ferriero G, Orlandini D, Amoresano A, Perucca L.

393 Measuring mobility in people with lower limb amputation: Rasch analysis of the

394 mobility section of the prosthesis evaluation questionnaire. J Rehabil Med.

$395 \quad 2007 ; 39(2): 138-44$.

396 5. Day SJ, Buis A. Cross cultural equivalence testing of the Prosthetic Evaluation

397 Questionnaire (PEQ) for an Arabic speaking population. Prosthet Orthot Int.

$398 \quad$ 2012;36(2):173-80. 
400 Brazilian Portuguese, cultural adaptation and validation of the Prosthesis Evaluation

401 Questionnaire. Jornal Vascular Brasileiro. 2015;14(2):110-114.

402

7. Safer VB, Yavuzer G, Demir SO, Yanikoglu I, Guneri FD. The prosthesis evaluation

403 questionnaire: reliability and cross-validation of the Turkish version. J Phys Ther Sci.

$404 \quad 2015 ; 27(6): 1677-80$.

405 8. Benavent JV, Igual C, Mora E, Antonio R, Tenias JM. Cross-cultural validation of 406 the Prosthesis Evaluation Questionnaire in vascular amputees fitted with prostheses in 407 Spain. Prosthet Orthot Int. 2015;40(6):713-9.

408 9. Boone DA, Coleman KL. Use of the Prosthesis Evaluation Questionnaire. JPO. 409 2006:18(6):P68-P79.

410 10. Wild D, Grove A, Martin M, Eremenco S, McElroy S, Verjee-Lorenz A et al.

411 Principles of good practice for the translation and cultural adaptation process for

412 patient-reported outcomes (PRO) measures: report of the ISPOR Task Force for

413 Translation and Cultural Adaptation. Value Health 2005;8:94-104.

414 11. Dewolf L, Koller M, Velikova G et al. Bottomley A. EORTC Quality of life group 415 translation procedure. 3rd ed., 2009.

416 12. Sintonen $\mathrm{H}$. The 15D instrument of health-related quality of life: properties and 417 applications. Ann Med 2001;33:328-36.

418 13. Stavem K. Reliability, validity and responsiveness of two multiattribute utility 419 measures in patients with chronic obstructive pulmonary disease. Qual Life Res. $420 \quad 1999 ; 8: 45-54$.

421 14. Alanne S, Roine RP, Räsänen P, Vainiola T, Sintonen H. Estimating the minimun 422 important change in the 15D scores. Qual Life Res. 2015;24(3):599-606. 
423 15. Price DD, McGrath PA, Rafii A, Buckingham B. The validation of visual analogue

424 scales as ratio scale measures for chronic and experimental pain. Pain 1983;17:45-56.

425 16. Cicchetti D, Bronen R, Spencer S, Haut S, Berg A, Oliver P, Tyrer P. Rating scales, 426 scales of measurement, issues of reliability: resolving some critical issues for clinicians 427 and researchers. J Nerv Ment Dis 2006;194(8):557-64.

428 17. Cronbach LJ. Coefficient alpha and the internal structure of tests. Psychometrika. $429 \quad 1951 ; 16(3): 297-334$.

430 18. McHorney CA, Tarlov AR. Individual-patient monitoring in clinical practice: are 431 available health status surveys adequate? Qual Life Res. 1995;4:293-307.

432 19. Streiner DL. Starting at the beginning: an introduction to coefficient alpha and 433 internal consistency. J Pers Assess 2003;80:99-103.

434 20. Streiner DL. Health measurement scales. A practical guide to their development and 435 use 3rd ed. New York: Oxford Medical Publications; 2003. 7p.

436 21. Beurskens AJ, de Vet HC, Koke AJ, van der Heijden GJ, Knipschild PG. Measuring 437 the functional status of patients with low back pain. Assessment of the quality of four 438 disease-specific questionnaires. Spine. 1995;20:1017-28.

439 22. Vaz S, Falkmer T, Passmore AE, Parsons R, Andreou P. The case for using the 440 repeatability coefficient when calculating test-retest reliability. PLoS One.

$441 \quad 2013 ; 8(9): \mathrm{e} 73990$.

442 23. Neljän elämänlaatumittarin sisältöanalyysi ICF-luokituksen viitekehyksessä. Journal 443 of Social Medicine. 2009;46(3):196-207.

444 24. Hawthorne G, Richardson J, Day NA. A comparison of the assessment of quality of 445 life (AQoL) with four other generic utility instruments. Ann Med 2001;33: 358-370.

446 25. Moock J, Kohlmann T. Comparing preference-based quality-of-life measures:

447 results from rehabilitation patients with musculoskeletal, cardiovascular, or 
448 psychosomatic disorders. Qual Life Res 2008;17:485-495.

449 26. Richardson J, Iezzi A, Khan MA, Chen G, Maxwell A. Measuring the Sensitivity 450 and Construct Validity of 6 Utility Instruments in 7 Disease Areas. Med Decis Making. $451 \quad 2016 ; 36: 147-59$.

452 27. Eskelinen E, Lepäntalo M, Hietala EM, Sell H, Kauppila L, Mäenpää I, Pitkänen J, 453 Salminen-Peltola P, Leutola S, Eskelinen A, Kivioja A, Tukiainen E, Lukinmaa A, 454 Brasken P, Railo M. Lower limb amputations in Southern Finland in 2000 and trends up 455 to 2001. Eur J Vasc Endovasc Surg. 2004;27(2):193-200.

456

457 
458 Table 1. Predefined hypotheses and their confirmation of rejection.

Statistical Method

Rejected/

Confirmed

\section{Reliability}

The floor and ceiling values are $\leq 15 \%$

Max or min scores in \%

$0 / 10^{*}$

Internal consistency $0.80-0.90$

Cronbach's alpha

$4 / 6^{*}$

Criterion validity

Moderate correlation between time of

Pearson

$10 / 0^{*}$

amputation and beginning of prosthesis use

Moderate correlation with general pain

Pearson

$3 / 7 *$

Moderate correlation with general health

Pearson

$4 / 6^{*}$

Convergent validity

Large correlation between the 15D and

Standardized regression

Ambulation

coefficients $\beta$.

Confirmed

Well-being

Confirmed

459 *Presents the number of confirmed and rejected hypotheses for all the 10 scales. $\beta$, beta. 
460 Table 2. Participants' sociodemographic and clinical characteristics.

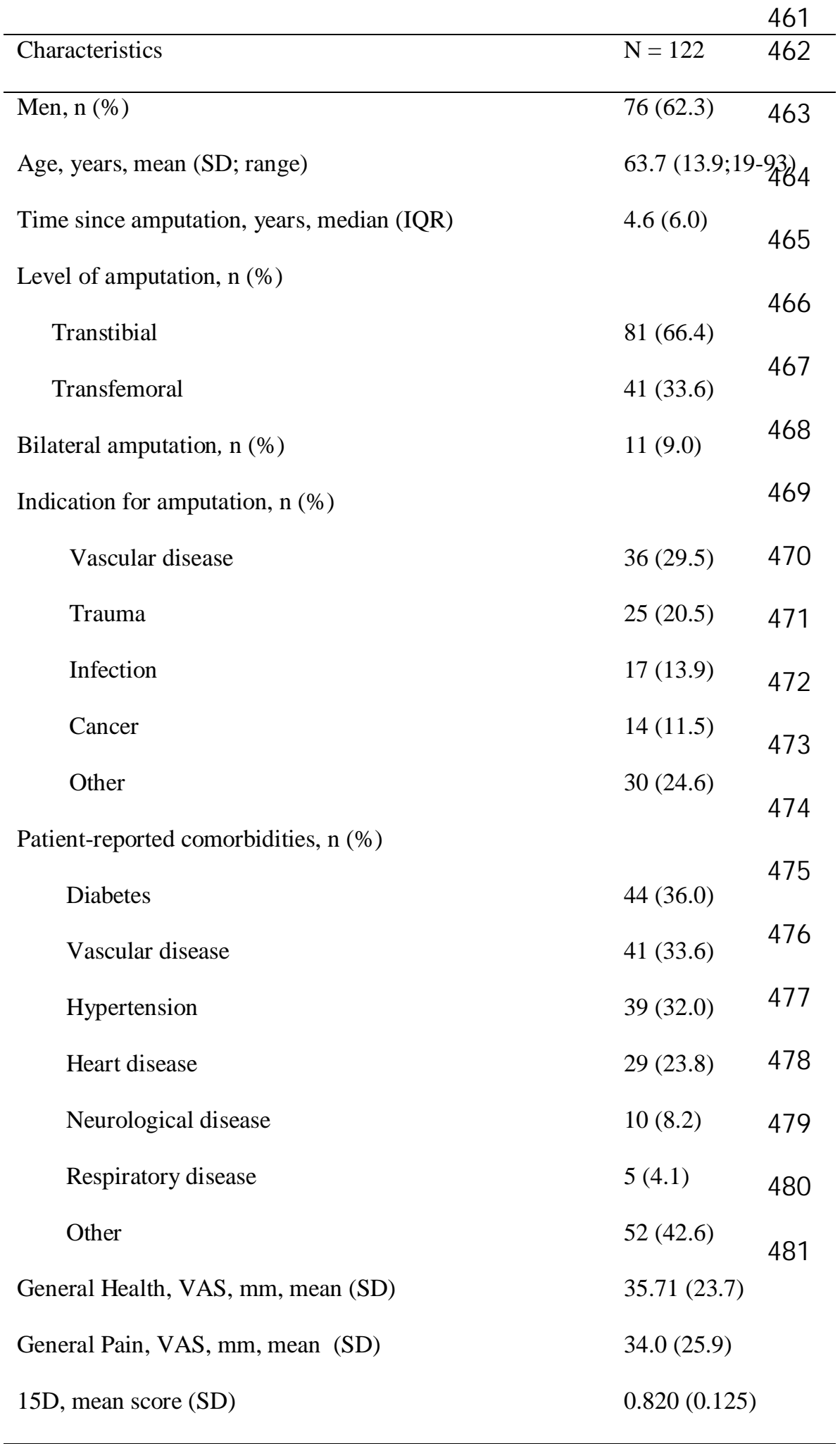

IQR, interquadral range; SD, standard deviation;

VAS, visual analogue scale 
482 Table 3. Mean scores, floor and ceiling effects and the internal consistency of each of

483 the scales at first administration.

\begin{tabular}{|c|c|c|c|c|c|c|c|}
\hline & Items & $\begin{array}{l}\text { Response } \\
\text { Rate }(\%)\end{array}$ & $\begin{array}{l}\text { Mean } \\
\text { Score } \\
\text { (SD) }\end{array}$ & $\begin{array}{l}\text { Score } \\
\text { Range }\end{array}$ & $\begin{array}{l}\text { Floor } \\
\text { Effect } \\
(\%)\end{array}$ & $\begin{array}{l}\text { Ceiling } \\
\text { Effect } \\
(\%)\end{array}$ & $\begin{array}{l}\text { Internal } \\
\text { Consistency } \\
(95 \% \mathrm{CI})^{*}\end{array}$ \\
\hline \multicolumn{8}{|l|}{ Prosthesis function } \\
\hline Usefulness & 8 & 100 & $64(19)$ & $7-95$ & 0 & 0 & 0.87 (0.83 to 0.92$)$ \\
\hline Residual Limb Health & 6 & 100 & $60(22)$ & $10-98$ & 0 & 0 & $0.79(0.70$ to 0.89$)$ \\
\hline Appearence & 5 & 100 & $62(21)$ & $4-99$ & 0 & 0 & $0.67(0.52$ to 0.82$)$ \\
\hline Sounds & 2 & 98 & $66(27)$ & $5-100$ & 0 & 2 & $0.82(0.71$ to 0.92$)$ \\
\hline \multicolumn{8}{|l|}{ Mobility } \\
\hline Ambulation & 8 & 100 & $52(28)$ & $0-96$ & 1 & 0 & 0.96 (0.95 to 0.97$)$ \\
\hline Transfers & 5 & 100 & $66(25)$ & $1-99$ & 0 & 0 & $0.81(0.75$ to 0.88$)$ \\
\hline \multicolumn{8}{|l|}{ Psychosocial experience } \\
\hline Perceived Responses & 5 & 100 & $83(17)$ & $14-100$ & 0 & 5 & $0.69(0.55$ to 0.83$)$ \\
\hline Frustration & 2 & 96 & $65(30)$ & $2-100$ & 0 & 3 & $0.85(0.76$ to 0.93$)$ \\
\hline Social Burden & 3 & 98 & $67(25)$ & $3-100$ & 0 & 2 & $0.75(0.65$ to 0.84$)$ \\
\hline \multicolumn{8}{|l|}{ Well-being } \\
\hline Well-being & 2 & 99 & $66(23)$ & $3-100$ & 0 & 1 & $0.80(0.68$ to 0.91$)$ \\
\hline
\end{tabular}

484 "Expresses the expected maximum size of $95 \%$ of the absolute differences between

485 paired observations. 95\% CI obtained by bias corrected and accelerated bootstrapping. 
487 Table 4. The change between the two measurements and reproducibility of each

488 separate PEQ scales.

Change From First to Reproducibility

Second Measurement

Mean $(95 \% \mathrm{CI}) \quad$ ICC $(95 \% \mathrm{CI}) * \quad \mathrm{CR}(95 \% \mathrm{CI}) * *$

\begin{tabular}{|c|c|c|c|}
\hline \multicolumn{4}{|l|}{ Prosthesis function } \\
\hline Usefulness & $0.6(-1.2$ to 2.3$)$ & $0.87(0.82$ to 0.91$)$ & $19(17$ to 23$)$ \\
\hline Residual Limb Health & $2.1(0.4$ to 4.7$)$ & $0.80(0.73$ to 0.86$)$ & $28(24$ to 31$)$ \\
\hline Appearence & $0.9(-1.1$ to 3.0$)$ & 0.85 (0.79 to 0.89$)$ & 22 (19 to 27$)$ \\
\hline Sounds & $1.7(-1.6$ to 4.9$)$ & $0.80(0.72$ to 0.86$)$ & $34(28$ to 40$)$ \\
\hline
\end{tabular}

Mobility

$\begin{array}{llll}\text { Ambulation } & 1.9(-0.7 \text { to } 4.5) & 0.87(0.82 \text { to } 0.91) & 28 \text { (23 to } 34) \\ \text { Transfers } & 1.5(-1.0 \text { to } 4.0) & 0.83(0.77 \text { to } 0.88) & 27(22 \text { to } 35)\end{array}$

Psychosocial experience

$\begin{array}{llll}\text { Perceived Responses } & 0.0(-1.9 \text { to } 2.0) & 0.78(0.70 \text { to } 0.84) & 21 \text { (16 to } 26) \\ \text { Frustration } & 0.4(-3.0 \text { to } 3.9) & 0.81(0.73 \text { to } 0.86) & 36 \text { (30 to } 43) \\ \text { Sosial Burden } & 2.0(-0.9 \text { to } 4.8) & 0.79(0.71 \text { to } 0.85) & 31 \text { (26 to } 35)\end{array}$

Well-being

Well-being $\quad 0.4(-2.6$ to 3.0$) \quad 0.79(0.71$ to 0.85$) \quad 28$ (24 to 32$)$

489 ICC, intraclass correlation coefficient; CR, coefficient of repeatability. *Obtained by

490 one-way random-effects model with absolute agreement. **Expresses the expected

491 maximum size of $95 \%$ of the absolute differences between paired observations. $95 \%$ CI

492 obtained by bias corrected and accelerated bootstrapping. 
495 Table 5. PEQ correlation with age, time between prosthesis and the assessment, and 496 general pain and health on visual analogue scale.

\begin{tabular}{lcccc}
\hline PEG Scale & Age & Time Since & General & General \\
& & Amputation & Pain & Health \\
\hline $\begin{array}{l}\text { Prosthesis function } \\
\text { Usefulness }\end{array}$ & $-0.28^{*}$ & 0.05 & $-0.39^{* * * *}$ & $-0.40^{* * *}$ \\
Residual Limb Health & 0.23 & 0.00 & $-0.30^{* * *}$ & -0.25 \\
Appearence & 0.15 & -0.05 & -0.23 & -0.17 \\
Sounds & 0.24 & -0.18 & -0.11 & -0.18
\end{tabular}

\section{Mobility}

$\begin{array}{lllll}\text { Ambulation } & -0.27 * & 0.18 & -0.44 * * * & -0.48 * * * \\ \text { Transfers } & -0.19 & 0.14 & -0.40 * * * & -0.40 * * *\end{array}$

Psychosocial experience

$\begin{array}{lllll}\text { Perceived responses } & -0.04 & 0.17 & -0.45^{* * *} & -0.42^{* * *} \\ \text { Frustration } & 0.04 & 0.10 & -0.10 & -0.05 \\ \text { Sosial Burden } & -0.23 & 0.19 & -0.40 * * * & -0.38 * * *\end{array}$

Well-being
Well-being
$-0.12$
0.11
$-0.48 * * * \quad-0.43 * * *$

${ }^{*} \mathrm{p}<0.05 ; * * \mathrm{p}<0.001 ; \mathrm{p}<0.0001 ;$ statistical significance calculated using Sidak-adjusted 498 probabilities.

499

500 Figure 1. Predictors of the 15D age- and gender-standardized regression coefficients $\beta$.

501 Values $0.10,0.30$ and 0.50 represent small, moderate and large correlations,

502 respectively. The box plot indicates mean values and the whiskers represent standard 503 deviations. 